(1.55, 1.64); MI 1.55 (1.46, 1.65); SD 1.30 (1.07, 1.58); stroke $1.37(1.29,1.45)$; CV death $1.45(1.35,1.57)$; and all thromboembolic events 1.47 (1.41, 1.54).

Conclusion In this study patients with a diagnosis of RA were $70 \%$ more likely to die and $30-40 \%$ more likely to suffer an acute major thromboembolic event compared with patients with a diagnosis of OA but not RA. In addition, patients with a diagnosis of RA were $60 \%$ more likely to die, and 30-50\% more likely to suffer an acute major thromboembolic event compared with patients with no arthritis diagnosis.

\section{OP0110 PERFORMANCE OF A TELEPHONE QUESTIONNAIRE ADMINISTERED BY LAY PEOPLE FOR CASE DETECTION OF RHEUMATOID ARTHRITIS AND SPONDYLARTHROPATHY}

F Guillemin, A Saraux, P Fardellone, P Guggenbuhl, JM Behier, J Coste. School of Public Health EA 1124, Faculty of Medicine, Vandoeuvre-Les-Nancy, France

\subsection{6/annrheumdis-2001.782}

Background Strategies for case detection in epidemiological surveys have explored the performance of questionnaires administered by mail, self-report or in face-to-face interview by health professionals, further confirmed by a rheumatologist. The cost of such strategies and the moderate validity of these methods has led to the preliminary development of a telephone questionnaire administered by lay people that would be useful for inflammatory rheumatic diseases.

Objectives To assess the accuracy of a questionnaire for epidemiological detection of rheumatoid arthritis (RA) and spondylarthropathies (SPA) suitable for telephone survey conducted by lay people.

Methods A questionnaire was created with a list of items derived from signs, symptoms, self-report diagnosis and currently accepted epidemiological criteria for classification of RA (ACR 1987) and SPA (ESSG 1991) by a group of rheumatologists and epidemiologists. RA, SPA and control patients were recruited in rheumatology outpatient clinics in 9 university hospitals in France. All patients were examined and had diagnosis confirmed by a certified rheumatologist. In each centre, lay people from self-help group or social league were trained by a unique team of professional poll staff to conduct a telephone interview in a standard manner using this questionnaire. Each group of RA and SPA was compared to the control group for sensitivity (Se) and specificity $(\mathrm{Sp})$ of each item and overall concordance with clinical diagnosis.

Results A total of 230 RA, 175 SPA and 195 controls with mean age of 55.6, 46.4 and 55.0 years, and female/male ratio of 2.6, 0.7 and 2.2 respectively were recruited. They were interviewed on the phone by 3 to 10 people in each centre. In RA-control comparison, a set of 5 items, most belonging to the ACR criteria, were found the most informative in logistic regression analysis, with self-report diagnosis showing the highest performance $(\mathrm{Se}=0.98, \mathrm{Sp}=0.86)$. In SPA-control comparison, a few items belonging to the set of ESSG criteria were the most informative, with self-report diagnosis showing the highest performance (Se $=0.85, \mathrm{Sp}=0.97)$. The overall concordance of each set with clinical diagnosis for RA and SPA was 98\% and 93\% respectively. When self-report diagnosis was not considered, queries on peripheral joint and spinal pain contributed to detection performance most significantly, with $90 \%$ and $78 \%$ concordance with clinical diagnosis of RA and SPA respectively. When modelling the selected items in a hypothetical population with $0.5 \%$ or $1 \%$ prevalence rate, the positive predictive value ranged from 4 to $26 \%$, and the negative predictive value was $99 \%$.

Conclusion A questionnaire using clinical diagnosis self-report and presentation of epidemiological criteria in common language by lay people has been developed. Given its performances in this sample at high risk for error of specificity, it is available for case detection in epidemiological survey in the general population, provided diagnosis is further confirmed by a certified rheumatologist as part of the case ascertainment strategy.

\section{OP0123 BODY MASS INDEX AND PHYSICAL ACTIVITY AS RISK FACTORS FOR PRIMARY OSTEOARTHRITIS. A COHORT STUDY IN 50.034 PERSONS}

${ }^{1} \mathrm{~GB}$ Flugsrud, ${ }^{2} \mathrm{~B}$ Espehaug, ${ }^{2} \mathrm{LI}$ Havelin, ${ }^{1} \mathrm{~L}$ Nordsletten, ${ }^{3} \mathrm{HE}$ Meyer. ${ }^{1}$ Oslo Orthopaedic University Clinic; ${ }^{2}$ The Norwegian Arthroplasty Register, Haukeland University Hospital, Bergen, Norway; ${ }^{3}$ National Health Screening Service, Oslo

10.1136/annrheumdis-2001.783

Background As no cure exists for osteoarthritis other than operation, it is important to identify preventable aetiological factors. Objectives To describe the association between middle age body mass index (BMI) and physical activity, and later total hip replacement (THR), in a large cohort.

Methods The Norwegian Arthroplasty Register records all THRs and hip revisions performed in Norwegian hospitals. ${ }^{1}$ In three Norwegian counties the National Health Screening Service (NHSS) three times conducted a cardiovascular screening during the years 1974-88. Persons born 1925-42 were screened repeatedly at median ages 42,47 and 53 years. $^{2}$ For $89 \%$ of the participants data on body weight and height were available at the NHSS from a screening for tuberculosis, conducted during the years 1963-75 (median age 34 years). ${ }^{3}$ The registers were matched and survival analyses performed using the Cox regression model. An event was recorded when a person had his first THR for primary osteoarthritis. Follow up was 1989-98. We controlled for age at screening, body height, marital status and smoking.

Results Analysing screening data from the second cardiovascular screening only (attendance 92.8\%) we found 672 THRs. A doseresponse relationship was found between BMI and the risk for THR. Women in the highest BMI quarter had a relative risk of 3.0 (95\% CI 2.2-4.2) compared to women in the lowest quarter. The corresponding figure in men was 2.0 (95\% CI 1.5-3.0). Physical activity at work also showed a dose-response relationship. Both women and men in the most active group had a relative risk for THR of 2.1 compared to the least active group.

Analyses of BMI data from each of the four screenings indicated that the predictive value of BMI for later THR was strongest at the tuberculosis screening and decreased gradually and considerably at the following screenings.

Conclusion This study confirmed that high physical activity at work increases the risk for THR-demanding osteoarthritis in men. Contrary to earlier findings, the effect was equally strong among women in our population. We found that even for levels of BMI and physical activity at work that were well within the normal ranges an increment in these risk factors increased the risk for THR-demanding osteoarthritis. Our findings indicate that the peak impact of BMI on the development of hip osteoarthritis may be at, or before, the age of 34 years. 


\section{REFERENCES}

1 Havelin LI, Espehaug B, Vollset SE, Engesæter LB, Langeland N. The Norwegian Arthroplasty Register. A survey of 17,444 total hip replacements. Acta Orthop Scand. 1993;64:245-51

2 National Health Screening Service, The cardiovascular disease study in Norwegian counties: results from second screening. Oslo: National Health Screening Service, 1988

3 Waaler HT. Height, weight and mortality. Acta Med Scand Suppl. 1984;679:1-56

\section{THU0240 EPIDEMIOLOGY OF OSTEOARTHRITIS IN NORTHERN ETHNIC GROUPS OF RUSSIA}

${ }^{1} \mathrm{~S}$ Erdesz, ${ }^{2} \mathrm{R}$ Protopopova, ${ }^{2} \mathrm{~V}$ Krivoshapkin. 'Epidemiology, Institute of Rheumatology, Moscow; ${ }^{2}$ Institute of Health, Yakutsk, Russia

\subsection{6/annrheumdis-2001.784}

Background Till present there are practically no information on the prevalence and risk factors of osteoarthritis in populations residing in severe climatic zones of Russia and subject to the influence of a number of unfavourable environmental factors.

Objectives To study the epidemiology of osteoarthritis among native population of rural areas of Siberian North - in Yakutia.

Methods Cross-sectional study of residents of four Yakutian settlements (North/North-Eastern part of Siberia) was performed. At the moment of the study 1282 persons aged 18 and more resided lived there. Among them 1216 persons (94.8\%) were examined. 1002 persons were Yakutians (Saha) and 214 Evenks.

Results Osteoarthritis was diagnosed in 218 settlement residents. Correspondingly the prevalence of $\mathrm{OA}$ in the population under study was $18.00 .8 \%$. Among women the OA prevalence was $22.51 .4 \%$ and among men $12.61 .4 \%(p<0.05)$. There was no reliable difference in prevalence between Yakuts and Evenks (correspondingly $17.3 \%$ and $21.0 \%, p<0.05$ ). We found linear correlation $(r=0.96)$ between frequency of OA and age.

Conclusion Thus, epidemiological study of osteoarthritis among rural population of Russian North demonstrated that the prevalence of the disease is $18.0 \%$ and women prevail and there is direct age relation between age and frequency of the disease.

\section{THU0241 BEHCET'S DISEASE: DOES LACK OF KNOWLEDGE RESULT IN UNDERDIAGNOSIS?}

${ }^{1} \mathrm{Y}$ Yazici, ${ }^{1} \mathrm{D}$ Erkan, ${ }^{2} \mathrm{G}$ Nesher, ${ }^{3} \mathrm{E}$ Kural, ${ }^{3} \mathrm{~N}$ Seyahi, ${ }^{4} \mathrm{~A}$ Ince. ${ }^{1}$ Rheumatology, Hospital for Special Surgery, New York, USA; ${ }^{2}$ heumatology, Shaare-Zedak Medical Center, Jerusalem, Israel; ${ }^{3}$ Internal Medicine, Cerrahpasa Medical Faculty, Istanbul, Turkey; ${ }^{4}$ Rheumatology, St Louis University Health Sciences Center, St Louis, USA

\subsection{6/annrheumdis-2001.785}

Background Prevalence of Behcet's disease has been estimated at $8-38 / 10,000$ in Turkey and $1-2 / 30,000$ in the USA. Pathergy test positivity is a major criterion for making the diagnosis of Behcet's disease.

Objectives To determine the knowledge among internal medicine (IM) residents from 2 different Mediterranean regions and 2 different regions in the USA regarding general rheumatology (GR), Behcet's disease, pathergy test and PPD test for tuberculosis.

Methods A 26-item questionnaire was developed including both closed and open-ended items, testing knowledge of GR, Behcet's disease, pathergy test, and PPD test. It was given to IM residents from 4 university centres (St. Louis University Health Sciences Centre (A) and Weill Medical College of Cornell University (B) in the USA, Shaare-Zedak Medical Centre (C) in Israel, and
Cerrahpasa Medical Faculty (D) in Turkey). In a single session, residents were asked 10 questions each about GR and Behcet's disease and 3 questions each about pathergy test and PPD. Rates of correct responses between IM residents from the USA and IM residents from Israel/Turkey were compared using Fischer's Exact test.

Results 69 residents participated in this study (A: 26, B: 13, C: 10, D: 20). The Table 1 shows the proportion of correct answers given for each category of questions. There was a statistically significant difference between the rate of correct responses among IM residents in the USA compared to those in Israel/Turkey with respect to the categories of GR, Behcet's disease, and pathergy test. This difference was more pronounced in the questions regarding Behcet's disease and pathergy test.

\begin{tabular}{lllll}
\multicolumn{5}{l}{ Abstract THU0241 Table 1 } \\
\hline & General rheumatology & PPD & Behcet's disease & Pathergy test \\
\hline United States & $33 \%$ & $61 \%$ & $35 \%$ & $21 \%$ \\
Israel/Turkey & $48 \%$ & $70 \%$ & $65 \%$ & $66 \%$ \\
p value & $<0.0002$ & 0.05 & $<0.0001$ & $<0.0001$ \\
\hline
\end{tabular}

Conclusion Knowledge of Behcet's disease, and especially pathergy test among IM residents tested is significantly lower in the USA than among those in Israel/Turkey. The difference in the prevalence of Behcet's disease in these two regions of the world may partly explain this disparity. Contrarily, lack of GR and Behcet's disease knowledge may contribute to decreased recognition and thus underdiagnosis of Behcet's disease resulting in the reported low prevalence in the US. Only by improving the education of internists with respect to Behcet's disease will the true prevalence of this condition be realised.

\section{THU0242 CAN SOCIAL SUPPORT AND SOCIAL NETWORK PREDICT THE EVOLUTION OF QUALITY OF LIFE OVER TIME IN EARLY RHEUMATOID ARTHRITIS? THE EURIDISS COHORT STUDY}

${ }^{1} \mathrm{~V}$ Demange, ${ }^{1} \mathrm{~F}$ Guillemin, ${ }^{1} \mathrm{M}$ Baumann, ${ }^{2} \mathrm{TP}$ Suurmeijer, ${ }^{3} \mathrm{~T}$ Moum, ${ }^{4} \mathrm{D}$ Doeglas, ${ }^{1} S$ Briançon, 'WJ Van den Heuvel. 'School of Public Health, Faculty of Medicine, University of Nancy, Vandoeuvre-Les-Nancy, France; ${ }^{2}$ Interuniversity Centre for Social Science Theory and Methodology; ${ }^{3}$ Department of Behavioural Sciences in Medicine, University of Oslo, Oslo, Norway; ${ }^{4}$ Department of Clinical Psychology, University of Groningen, Groningen, The Netherlands

\subsection{6/annrheumdis-2001.786}

Background There is clear epidemiological evidence for a relationship between social support and health. Though, the mechanism remains unclear whether a poor social support precedes or follows a poor health status. Rheumatoid arthritis (RA) is a chronic inflammatory disease affecting particularly quality of life.

Objectives First, to investigate cross-sectional relationships between quality of life and social support (SS) and support network (SN) in patients with early RA. Then to look at how baseline SS or SN influence quality of life over time; and last, to explore how variations over time in SS or SN affect quality of life over time.

Methods Subjects were members of the EURIDISS populationbased cohort from France, the Netherlands and Norway, and had suffered from RA for less than 5 years. Yearly assessments 